\title{
Pain on injection with propofol
}

\author{
Soo Kyung Lee \\ Department of Anesthesiology and Pain Medicine, Hallym University College of Medicine, Anyang, Korea
}

The use of propofol often results in pain on injection, which is sometimes very distressing to patients. In analysis of 6,264 patients in 56 reports, $70 \%$ of all control patients reported some degree of pain or discomfort on injection with propofol [1]. In 1998, Tan and Onsiong [2] suggested that a wise choice would be to use a combination of techniques, such as alfentanil pretreatment, mixing lidocaine with the propofol and injecting into a large vein with no carrier fluid to decrease the incidence and severity of propofol injection pain.

McCrirrick and Hunter [3] found that administering propofol at $4^{\circ} \mathrm{C}$, significantly reduces the incidence of injection pain. Prior injection of cold saline reduces the incidence of pain and discomfort significantly compared with unmodified propofol and is similar to that after cold propofol and propofol with lidocaine [4]. However, the incidence of pain with cold propofol and lidocaine is not statistically different from room temperature propofol and lidocaine in children [5]. Cho et al. [6] assessed the effectiveness of cold propofol and pretreatment with remifentanil in minimizing pain associated with the injection of propofol and investigated whether a combination of cold propofol and remifentanil produced additional analgesic efficacy. They found that a combination treatment with $0.5 \mu \mathrm{g} /$ $\mathrm{kg}$ remifentanil pretreatment and cold propofol significantly reduces the incidence and severity of propofol injection pain compared with each treatment used alone.

The aqueous phase, which contains free propofol, is known to be associated with the intensity of pain at the injection site. Yamakage et al. [7] recommended the use of propofol mediumchain triglyceride (MCT)/long-chain triglyceride (LCT) for reducing pain on injection, because the concentrations of free propofol are significantly smaller by $30-45 \%$ than those in propofol LCT. Mallick et al. [8] reported that premixing 40 mg of lidocaine to Lipuro ${ }^{\circledR}$ propofol (a propofol formulated as an emulsion of 50\% MCT and 50\% LCT) almost abolishes the pain on injection, making induction of anesthesia less painful compared to Lipuro ${ }^{\circledR}$ propofol alone or Diprivan ${ }^{\circledR}$ propofol (a propofol formulated as an emulsion in a solution of $10 \%$ soybean oil containing only LCT) with lidocaine.

A lipid-free microemulsion propofol (Aquafol ${ }^{\circledR}$ ) was developed to avoid the risk of lipid solvent-related adverse drug reactions, and the efficacy and safety are not different from those of Diprivan ${ }^{\circledR}$ [9]. Microemulsion propofol produces more frequent and severe pain on injection than lipid emulsion propofol, a difference that may be attributable to the seven-fold higher concentration of aqueous free propofol [10]. Kim et al. [11] investigated the effect of a lidocaine mixture on microemulsion propofol injection pain and sought to determine the optimal dose of lidocaine that reduced pain on injection of propofolidocaine mixture. They used 20, 30, and $40 \mathrm{mg}$ lidocaine, and the incidence of pain was $80 \%, 65 \%$, and $50 \%$, respectively, compared with $97.5 \%$ in a control group. Within this lidocaine dose range, increasing the lidocaine dose significantly lessened the pain during injection of microemulsion propofol. However, it is difficult to conclude that $40 \mathrm{mg}$ of lidocaine is an optimal dose because a $50 \%$ incidence of injection pain is too high.

Although several single or combination methods with lipid emulsion propofol nearly abolish pain on injection, further studies to search for an effective and safe method to reduce pain on injection, especially with microemulsion propofol, are needed until a better and safer propofol is available for clinical use in the near future.

Corresponding author: Soo Kyung Lee, M.D., Ph.D., Department of Anesthesiology and Pain Medicine, Hallym University Sacred Heart Hospital, Hallym University College of Medicine, 896, Pyeongchon-dong, Dongan-gu, Anyang 431-070, Korea. Tel: 82-31-380-3945, Fax: 82-31385-3244, E-mail: agnetask@yahoo.co.kr

(c) This is an open-access article distributed under the terms of the Creative Commons Attribution Non-Commercial License (http:// creativecommons.org/licenses/by-nc/3.0/), which permits unrestricted non-commercial use, distribution, and reproduction in any medium, provided the original work is properly cited. 


\section{References}

1. Picard P, Tramèr MR. Prevention of pain on injection with propofol: a quantitative systematic review. Anesth Analg 2000; 90: 963-9.

2. Tan $\mathrm{CH}$, Onsiong MK. Pain on injection of propofol. Anaesthesia 1998; 53: 468-76.

3. McCrirrick A, Hunter S. Pain on injection of propofol: the effect of injectate temperature. Anaesthesia 1990; 45: 443-4.

4. Barker P, Langton JA, Murphy P, Rowbotham DJ. Effect of prior administration of cold saline on pain during propofol injection. A comparison with cold propofol and propofol with lignocaine. Anaesthesia 1991; 46: 1069-70.

5. Pickford A, Burden J, Lewis I. Propofol and pain on induction: the effect of injectate temperature in children. Paediatr Anaesth 2000; 10: 129-32.

6. Cho SY, Jeong CW, Jeong CY, Lee HG. Efficacy of the combination of cold propofol and pretreatment with remifentanil on propofol injection pain. Korean J Anesthesiol 2010; 59: 305-9.
7. Yamakage M, Iwasaki S, Satoh J, Namiki A. Changes in concentrations of free propofol by modification of the solution. Anesth Analg 2005; 101: 385-8.

8. Mallick A, Elliot SC, Krishnan K, Vucevic M. Lidocaine is more effective than the choice of propofol formulations to reduce incidence of pain on induction. Eur J Anaesthesiol 2007; 24: 403-7.

9. Kim KM, Choi BM, Park SW, Lee SH, Christensen LV, Zhou J, et al. Pharmacokinetics and pharmacodynamics of propofol microemulsion and lipid emulsion after an intravenous bolus and variable rate infusion. Anesthesiology 2007; 106: 924-34.

10. Sim JY, Lee SH, Park DY, Jung JA, Ki KH, Lee DH, et al. Pain on injection with microemulsion propofol. Br J Clin Pharmacol 2009; 67:316-25.

11. Kim HS, Cho KR, Lee JH, Kim YH, Lim SH, Lee KM, et al. Prevention of pain during injection of microemulsion propofol: application of lidocaine mixture and the optimal dose of lidocaine. Korean J Anesthesiol 2010; 59: 310-3. 